\title{
Concussions are Brain Injuries and Should be Taken Seriously
}

Can. J. Neurol. Sci. 2009; 36: 269-270

Concussions occur frequently in hockey in Canada, both at the amateur and professional levels ${ }^{1-3}$. It has been estimated that the incidence could be as high as $20 \%$ of players per hockey team annually sustain concussions. Although concussions often occur in motor vehicle crashes, falls, and injuries at work, repeated concussions are more frequent in sports. Current medical and public health opinion is overwhelming that concussions should be taken seriously by the sports and recreation community. There is some evidence that this is beginning to happen, but more needs to be done to protect our athletes, both young and old. There is concern that concussions especially repeated concussions may not only cause acute major damage such as the rare, but potentially fatal second impact syndrome, but also chronic brain damage. Indeed, it is now apparent that repeated concussions can cause permanent severe cognitive deficits such as dementia, and other major sequelae such as depression, suicide, and even homicide. A dementing syndrome similar to dementia pugilistica occurs in other sports that cause repeated concussions. Recently, a group of neuropsychologists at the University of Montreal reported that even a single severe concussion in athletes can produce permanent sequelae ${ }^{4}$.

The specific concern about hockey stems from the high incidence of concussions in this sport, and the large number of players in Canada. In his paper in this edition of the Canadian Journal of Neurological Sciences, Cusimano ${ }^{5}$ stated that hockey is the sport with the highest number of concussions in Canada. Hockey is also a sport with a relatively high risk of catastrophic injury to individual players and to society in general, defined as the number of catastrophic injuries per 100,000 participants and per 100,000 population, respectively ${ }^{6,7}$.

In view of the frequency of repeated concussions in this sport, hockey is a major public health concern in Canada, and many injury prevention strategies are being mobilized to deal with it. These include strategies to prevent concussion from happening in the first place, (primary prevention), and strategies to prevent the long-term sequelae of repeated concussion (secondary prevention). Prevention measures are essential since there is no treatment to hasten or ensure complete recovery from concussion, and no treatment for the serious long-term complications such as dementia.

\section{Strategies to Prevent Concussion}

\section{Elimination of Hits to the Head}

The age of introduction of bodychecking has been examined as a potential measure for preventing concussion, and as stated in the Cusimano article ${ }^{5}$, bodychecking is an important cause. Goodman et $\mathrm{al}^{1}$ showed that the head striking the boards is the most frequent mechanism of injury. Many of these incidents are related to being bodychecked into the boards. Elbow and shoulder hits to the head are other frequent causes that can be eliminated. Falls to the ice or against the goal post are other important causes, and these are more difficult to reduce. There are other suggestions to eliminate hits to the head such as fouron-four hockey to reduce collisions ${ }^{8}$.

\section{Elimination of Fighting}

Fighting causes a significant number of concussions, $6 \%$ in the series of Goodman et $\mathrm{al}^{1}$, and is now more recognized as a cause of brain injury because of the death of Don Sanderson in 2008.

\section{Helmets and Helmet Buckles}

Everyone on the ice should be helmeted at all times and the helmets should fit well and be buckled snugly. Helmets prevent other brain injuries such as contusions, lacerations and blood clots. Greater efforts should be directed towards enhancing awareness that helmets do not prevent the majority of concussions, and that there is no concussion proof helmet. Buckles fastened at "one-finger snugness" will stay on the head after the first blow and protect the brain from the second blow, usually impact with the ice or boards. Also, cages and full face protection are better than half visors or no face protection ${ }^{9}$.

\section{Other Protective Equipment}

There is major concern that the hardness of other protective equipment worn by hockey players, especially shoulder and elbow pads, has exceeded the requirements for protection, and instead has contributed to concussion. Indeed, some players have become adept at delivering knockout blows to the head with their shoulder pads. All these "protective" pads should have an energy absorbing external surface to protect the head of the opposing player.

\section{Educational Efforts}

Cusimano's study 5 is heartening in some respects and worrisome in others. It is encouraging that about $80 \%$ of players knew that the occurrence of a head injury should stop a player from continuing in a game, and that the player should inform the coach or trainer. However, players and the parents and coaches showed major deficiencies in their knowledge of the diagnosis and management of concussions. It is clear that greater educational efforts are required to expand the players and coaches' knowledge of concussions. Recently, it has been shown that a significant number of hockey players are not compliant with the medical advice given to them about concussion management ${ }^{10}$ another indication of the need for enhanced 
concussion education. In the past five years, several educational programs have been developed in Canada by organizations including Hockey Canada, the Dr. Tom Pashby Sports Safety Fund, the Canadian Spinal Research Organization, Ontario Neurotrauma Foundation, ThinkFirst Canada, and the National Hockey League Players Association. These efforts have included traveling presentations ("Concussion Road Shows"), brochures and pamphlets, "concussion cards", and a website containing concussion education materials for players, parents, coaches, trainers and health care professionals (www.thinkfirst.ca). Some of these efforts have been proven to be evidence-based ${ }^{11}$.

\section{The Media}

The media play an extremely important role in prevention of concussion. The media can enhance public awareness of the recognition, management and importance of concussion. As well, the media can advocate for primary prevention of concussion. Cusimano ${ }^{5}$ was critical of the negative role of some media commentators who advise return to play after a head injury, and encourage disregard for the seriousness of concussion.

\section{The Professionals}

As pointed out by Cusimano ${ }^{5}$, the professionals have a major role to play in the incidence of concussions. If the professionals showed greater respect for their own bodies and the bodies of opponents, so would the amateurs. Thus, injury prevention efforts should be from the top-down as well as from the bottomup.

\section{Better Surveillance}

There is a need for enhanced surveillance of concussion in sport. Much of the available incidence data antedates the development of a more reliable and universally accepted definition of concussion. The current definition has only recently been established as a result of an international committee of experts that included Canadian authorities such as Karen Johnston and Mark Aubry ${ }^{12}$. Data relying on older definitions based on the premise of loss of consciousness being a necessary component would miss approximately $95 \%$ of concussions which do not include loss of consciousness. Accurate incidence data is essential for monitoring the effectiveness of injury prevention measures. For example, prevention programs against spinal injuries in hockey have been effective based on monitoring by a comprehensive registry that tracks all spinal injuries in hockey in Canada ${ }^{13}$. Tracking of the incidence of concussion in hockey will be much more difficult because of the very large numbers involved (at least 20 times greater incidence than spinal injuries). Under-reporting of concussions is also a significant problem in data collection ${ }^{14}$. A registry would be prohibitively costly, and thus surveillance methods must be established.

\section{Coordination of Prevention Efforts}

It is encouraging that a coalition called the Hockey Neurotrauma and Concussion Initiative was formed in 2008 led by the Ontario Neurotrauma Foundation to address the prevention of concussions in hockey.
Cusimano ${ }^{5}$ is commended for his study emphasizing the need for greater education and other prevention efforts concerning concussion in Canadian hockey.

Charles H. Tator

Toronto, Ontario

\section{REFERENCES}

1. Goodman D, Gaetz M, Meichenbaum D. Concussions in hockey: there is cause for concern. Med Sci Sports Exerc. 2001;33: 2004-9.

2. Wennberg RA, Tator CH. National Hockey League reported concussions, 1986-87 to 2001-02. Can J Neurol Sci. 2003;30:206-9.

3. Wennberg RA, Tator CH. Concussion incidence and time lost from play in the NHL during the past ten years. Can J Neurol Sci. 2008;35:647-51.

4. De Beaumont L, Theoret H, Mongeon D, Leclerc S, Tremblay S, Ellemberg D, et al. Brain function decline in healthy retired athletes who sustained their last sports concussion in early adulthood. Brain. 2009 Mar;132(Pt 3):695-708. Epub 2009 Jan 28.

5. Cusimano M. Canadian minor hockey participants' knowledge about concussion. Can J Neurol Sci. 2009;36:315-20.

6. Tator CH. Overview of the results of the Ontario study, 1986-1995. In: Tator $\mathrm{CH}$, editor. Catastrophic Injuries in sports and recreation, causes and prevention: a Canadian study. Toronto: University of Toronto Press; 2008. p. 21-57.

7. Saleh F, Tator $\mathrm{CH}$. Ice hockey. In: Tator $\mathrm{CH}$, editor. Catastrophic injuries in sports and recreation, causes and prevention: a Canadian Study. Toronto: University of Toronto Press; 2008. p. 291-304.

8. Moore M. Saving the Game. Pro hockey's quest to raise its game from crisis to new heights. Toronto: McClelland and Stewart; 2006.

9. Benson BW, Rose MS, Meeuwisse WH. The impact of face shield use on concussions in ice hockey: a multivariate analysis. Br J Sports Med. 2002;36:27-32.

10. Ackery A, Provvidenza C, Tator C. Concussion and Other Head Injuries in Hockey: Compliance with Return to Play Advice and Follow-up Status. Can J Neurol Sci. In Press 2009.

11. Cook DJ, Cusimano MD, Tator CH, Chipman ML. Evaluation of the ThinkFirst Canada, smart hockey, brain and spinal cord injury prevention video. Inj Prev. 2003;9:361-6.

12. McCrory P, Johnston K, Meeuwisse W, Aubry M, Cantu R, GrafBaumann T, et al. Summary and agreement statement of the 2nd International Conference on Concussion in Sport, Prague 2004. Br J Sports Med. 2005;39:196-204.

13. Tator CH, Provvidenza CF, Lapczak L, Carson J, Raymond D. Spinal injuries in Canadian ice hockey: documentation of injuries sustained from 1943-1999. Can J Neurol Sci. 2004;31: 460-6.

14. Williamson IJ, Goodman D. Converging evidence for the underreporting of concussions in youth ice hockey. Br J Sports Med. 2006;40:128-32. 